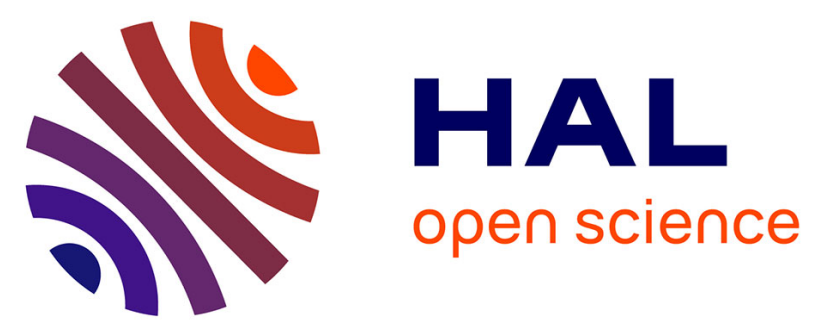

\title{
Environmentally benign glycosylation of aryl pyranosides and aryl/alkyl furanosides demonstrating the versatility of thermostable CGTase from Thermoanaerobacterium sp.
}

Alizé Pennec, Laurent Legentil, Luis Herrera-Estrella, Vincent Ferrières, Anne-Laure Chauvin, Caroline Nugier-Chauvin

\section{To cite this version:}

Alizé Pennec, Laurent Legentil, Luis Herrera-Estrella, Vincent Ferrières, Anne-Laure Chauvin, et al.. Environmentally benign glycosylation of aryl pyranosides and aryl/alkyl furanosides demonstrating the versatility of thermostable CGTase from Thermoanaerobacterium sp.. Green Chemistry, 2014, 16, pp.3803. 10.1039/C4GC00631C . hal-01075732

\section{HAL Id: hal-01075732}

https://hal-univ-rennes1.archives-ouvertes.fr/hal-01075732

Submitted on 20 Oct 2014

HAL is a multi-disciplinary open access archive for the deposit and dissemination of scientific research documents, whether they are published or not. The documents may come from teaching and research institutions in France or abroad, or from public or private research centers.
L'archive ouverte pluridisciplinaire HAL, est destinée au dépôt et à la diffusion de documents scientifiques de niveau recherche, publiés ou non, émanant des établissements d'enseignement et de recherche français ou étrangers, des laboratoires publics ou privés. 


\title{
Environmentally benign glycosylation of aryl pyranosides and aryl/alkyl furanosides demonstrating the versatility of thermostable CGTase from Thermoanaerobacterium sp.
}

\author{
Alizé Pennec $^{b, c}$, Laurent Legentil*b,c, Luis Herrera-Estrella ${ }^{a}$, Vincent Ferrières ${ }^{b, c}$, Anne-Laure \\ Chauvin*a and Caroline Nugier-Chauvin*b,c \\ a Laboratorio Nacional de Genómica para la Biodiversidad (Langebio), CINVESTAV-IPN, Km \\ 9.6 Lib. Nte, Carr. Irapuato - León, CP36821, Irapuato, México. Fax +52 462607 8276; Tel: \\ +524621663000. \\ b Ecole Nationale Supérieure de Chimie de Rennes, CNRS, UMR 6226, 11 allée de \\ Beaulieu, CS 50837, 35708 Rennes Cedex 7, France. Tel: +33 223238 140; E-mail: \\ laurent.legentil@ensc-rennes.fr
}

${ }^{\mathrm{c}}$ Université européenne de Bretagne

An extensive study on the specificity of transglycosylation and disproportionation of Thermoanaerobacterium $s p$. cyclodextrin glucosyltranferases against aryl glucopyranosides or furanosides was achieved. While a mixture of maltoside and isomaltoside was obtained respectively using $p$-nitrophenyl glucopyranoside as acceptor, only one regioisomer, namely the $p$-nitrophenyl $\alpha$-D-Glcp-(1,3)- $\alpha$-L-Araf was isolated using $p$-nitrophenyl arabinofuranoside as acceptor. Interestingly, similar outcomes were found when using p-nitrophenyl galactofuranoside. Furthermore, activation by microwave irradiation resulted in faster reaction times and higher yields and led to glucosidic oligosaccharides with up to $70 \%$ conversion. The influence of the anomeric and C-4 configurations of the glycosidic acceptors on the transglycosylation, previously stated for the CGTase family, was not observed and unconventional substrate specificity towards alkyl furanosides was highlighted.

\section{Introduction}

Glycoconjugates incorporating rare furanosides are nowadays gaining momentums for detergent applications and also as new therapeutics. Indeed, while alkyl C-glycofuranosides were sought for their amphiphilic properties, ${ }^{1}$ oligomers of L-arabinofuranose were described as potential immunomodulators as they stimulate the secretion of various cytokines by macrophages. ${ }^{2}$ Furthermore, alkyl derivatives like the octyl $\beta$-D-galactofuranoside have exhibited mycobacteriostatic properties ${ }^{3-5}$ and are detrimental for the survival of Leishmania donovani and infection of macrophages by the parasite. ${ }^{6}$ Recently, we described the access to such monosaccharides from renewable resources thanks to a one-pot biocatalyzed furanosylation of various alcohols in presence of an arabinofuranosidase of the GH 51 family. ${ }^{7}$ Such strategy used furanosyl donors for transglycosylation. However, the 
transglycosylation on furanoside acceptors and in particular the selective formation of alkyl glucopyranosyl-furanoside conjugates by enzymatic means has still to be developed. Such scaffold can be found in the exopolysaccharide expressed by Lactobacillus rhamnosus, ${ }^{-}$ some strains of Streptococcus thermophilus ${ }^{9}$ or as a disaccharide unit grafted to some natural flavonoids. ${ }^{10}$ Such architectures found applications in the food industry as thickening agent for example.

Intermolecular transglycosylation catalyzed by cost-effective catalysts is key process for the synthesis of high value carbohydrate-based substrates from donors extracted from biomass. Within the available catalysts, cyclodextrin glucosyltransferase enzymes (CGtase, E.C. 2.4.1.19) are starch degrading enzymes belonging to the important family of endo-glycosyl transferases. ${ }^{11}$ Further hydrolysing starch [ $\alpha-1,4$-hydrolysis], the enzyme also catalyzes linear oligosaccharide disproportionation as well as cyclic and linear dextrin coupling, depending on the bacterial source involved (Fig. 1). ${ }^{12}$

Substrate specificity of CGtases has been extensively studied and demonstrated the efficiency of CGtases to transglycosylate several glucosyl units onto analogs of glucopyranoside. $\frac{13}{}$ Additionally, it was highlighted that derivatization of the acceptor at $\mathrm{C}-1$ did not exhibit significant differences in activity whereas changing the configuration at the C-2 and C-4 hydroxyl groups resulted in serious loss of the CGTase efficiency. ${ }^{14}$ Nakamura et al. showed also by analogy with $\alpha$-amylase that a pNP group on the anomeric position of the acceptor is not detrimental to the catalysis. ${ }^{15}$ Finally, transglycosylation on dodecyl maltoside was recently performed and allowed the access to alkyl oligoglucosides with non-ionic surfactant properties. ${ }^{16}$ Such results demonstrated the high versatility of the CGTase family towards various acceptors. Nevertheless its potential for glucosylation of alkyl furanosides has still to be evaluated.

Thus, in this study the intermolecular transglycosylation and disproportionation reactions of the CGTase of Thermoanaerobacterium sp. (EC 2.4.1.19) or Toruzyme ${ }^{\circledR} 3.0 \mathrm{~L}$, against pyranosidic and furanosidic acceptors, were compared. In addition, conventional and microwave-assisted reactions (MAR) conditions were evaluated with both substrate types. To achieve this goal, readily available, low cost and bearing a chromogenic anomeric group compounds; $p$-nitrophenyl $\alpha / \beta$-D-glucopyranoside ( $p N P \alpha$-Glcp 1 and $p N P \beta$-Glcp 2) and furanoside targets, $p$-nitrophenyl $\alpha$-L-arabinofuranoside ( $p$ NP $\alpha$-Araf 3 ) and $p$-nitrophenyl $\beta$-Dgalactofuranoside ( $p N P \beta$-Galf 4), were considered (Fig. 2). The method was eventually extended to alkyl furanosides 5 to 11 as acceptors owing to their potential as therapeutics and surfactants. 
Fig. 1 Reactions catalyzed by cyclodextrin glucosyle transferases.

\section{Results and discussion}

To evaluate the scope of glucosyl transfer, the reaction was first performed with UV-active pyranosides and furanosides 1 to 4 (Fig. 2). Recently, Yoon and Robyt demonstrated that the acceptor/donor ratio influences the degree of polymerization (DP) of the oligoglucanes generated and that a ratio higher than 3 favoured transglycosylation/disproportionation reaction over cyclization. ${ }^{17}$ Consequently, all acceptors 1 to 4 and $\beta$-cyclodextrin, in a ratio of $7 / 2$, were incubated for 72 hours in $50 \mathrm{mM}$ phosphate buffer $\mathrm{pH} 6$ at $50^{\circ} \mathrm{C}$ in the presence of Toruzyme $^{\circledR} 3.0 \mathrm{~L}(0.05 \mathrm{mg} / \mathrm{mL})$. These conditions were described as optimum for CGTase glucosylation. ${ }^{18}$

Fig. 2 p-Nitrophenyl and alkyl glycosides used as acceptor.

After 72 hours, the reaction mixture was analyzed by liquid chromatography coupled to mass spectrometry (LC-MS). For each substrate, the chromatogram showed a succession of peaks with decreasing intensities (See ESI). The peaks with the shortest retention times 
corresponded to the remaining starting $p N P$ glycosides according to mass analysis (peak at $3.80 \mathrm{~min}$ for $\mathbf{1}, 3.64 \mathrm{~min}$ for $2,3.38 \mathrm{~min}$ for 3 and $3.22 \mathrm{~min}$ for 4 ). The MS spectra also indicated a mass difference of 162 between each major consecutive peak which is characteristic of a molecule of glucose minus one molecule of water. This confirmed the successive transfer of one glucosyl unit to the $p N P$ glycoside backbone to form $p N P$ Glc $p_{n^{-}}$ glycoside. Furthermore, with compound $\mathbf{1}$, an additional signal at $\mathrm{m} / \mathrm{z} 139$ corresponding to the $p$-nitrophenol group was present. It is most likely due to the hydrolysis of compound $\mathbf{1}$ or its use as donor by the CGTase. Indeed 1 had the same $\alpha$-configuration than cyclodextrin or malto-oligosaccharides, both substrates of CGTase. ${ }^{19}$

Integration of relevant peaks on the chromatograms led to estimate the percentage of the remaining starting acceptors, the oligosaccharides formed and the subsequent hydrolysis (Table 1). Overall transglycosylation reached 67, 89 and 59\% with acceptors 2, 3 and 4, respectively (Entries 2 to 4), but only $23 \%$ with 1 (Entry 1). This data corroborated the significant hydrolysis of the $\alpha$-D-glycosidic bond (55\%) by the CGTase. Nevertheless, oligomers with degree of polymerization up to 10 could be detected in the reaction mixture whatever the nature of the substrate. The di- and trisaccharides were the main products from the reaction, and corresponded to the transfer of one or two glucosyl entities from the cyclodextrin. It highlighted the prevalence of transglycosylation over disproportionation.

Table 1 Conversion yield of the reaction between cyclodextrin and $p$ NP $\alpha / \beta$-glycoside in presence of CGTase. from Thermoanaerobacterium sp.

\begin{tabular}{|c|c|c|c|c|c|c|c|c|}
\hline \multirow[b]{2}{*}{ Entry } & \multirow[b]{2}{*}{ Acceptors } & \multirow{2}{*}{$\begin{array}{c}\text { Remaining } \\
\text { acceptor (\%) }\end{array}$} & \multirow[b]{2}{*}{ Hydrolysis (\%) } & \multirow{2}{*}{$\begin{array}{c}\text { Trans- } \\
\text { glycosylation } \\
(\%)\end{array}$} & \multicolumn{4}{|c|}{$\%$ of conversion } \\
\hline & & & & & $\begin{array}{l}p \text { NP Glcp- } \\
\text { glycoside }\end{array}$ & $\begin{array}{c}p \mathrm{NP} \mathrm{Glc} p_{2^{-}} \\
\text {glycoside }\end{array}$ & $\begin{array}{c}p \mathrm{NP} \mathrm{Glc}_{3^{-}} \\
\text {glycoside }\end{array}$ & $\begin{array}{l}p \mathrm{NP} \text { Glc } p_{4-} \\
\text { glycoside }\end{array}$ \\
\hline 1 & $p$ NP $\alpha-\mathrm{D}-\mathrm{Glc} p(\mathbf{1})$ & 22 & 55 & 23 & 10 & 7 & 6 & trace \\
\hline 2 & $p$ NP $\beta$-D-Glc $p$ (2) & 28 & 0 & 67 & 36 & 18 & 9 & 4 \\
\hline 3 & $p$ NP $\alpha$-L-Ara $f(3)$ & 11 & 0 & 89 & 41 & 21 & 13 & 9 \\
\hline 4 & $p$ NP $\beta$-D-Gal $f(4)$ & 40 & 1 & 59 & 32 & 16 & 7 & 4 \\
\hline
\end{tabular}

To confirm these initial results, the kinetic profiles of the enzymatic reactions with each substrate were performed (Fig. 3). As expected, the plots showed a decrease in the amount of acceptor over time. The pyranosidic substrates were rapidly consumed after only 2 hours whereas less than $40 \%$ of $p$ NP Araf 3 and $25 \%$ of $p$ NP Galf 4 were glycosylated after $5 \mathrm{~h}$ indicating a slower reaction rate for the furanosidic vs. pyranosidic acceptors. When 1 was used as acceptor, the transglycosylation rate reached a maximum after just $2 \mathrm{~h}$, and then the amount of all resulting oligosaccharides decreased over time. Again, this was a proof that the $p N P \alpha$-D-GIcp and the resulting pNP oligosides were acceptors and donors of the CGTase. With 2, $\mathbf{3}$ and $\mathbf{4}$ as acceptor, the amount of all reaction products reached a steady state after $30 \mathrm{~h}$ and the global conversion remained stable. Therefore, the resulting $p N P$ glycosides 
were not consumed during the course of the reaction and thus are not themselves donors for the CGTase. Furthermore such plateau is characteristic of a ratio acceptor/donor below 3 where cyclization of linear maltoside back to cyclodextrin is favoured over transglycosylation. ${ }^{17}$ The furanosides $\mathbf{3}$ and $\mathbf{4}$ demonstrated a good response to transglycosylation, and the sugar cyclic size did not affect the reaction yield. This result confirmed the large reaction scope of the CGTase towards pento- and hexofuranosidic acceptors.
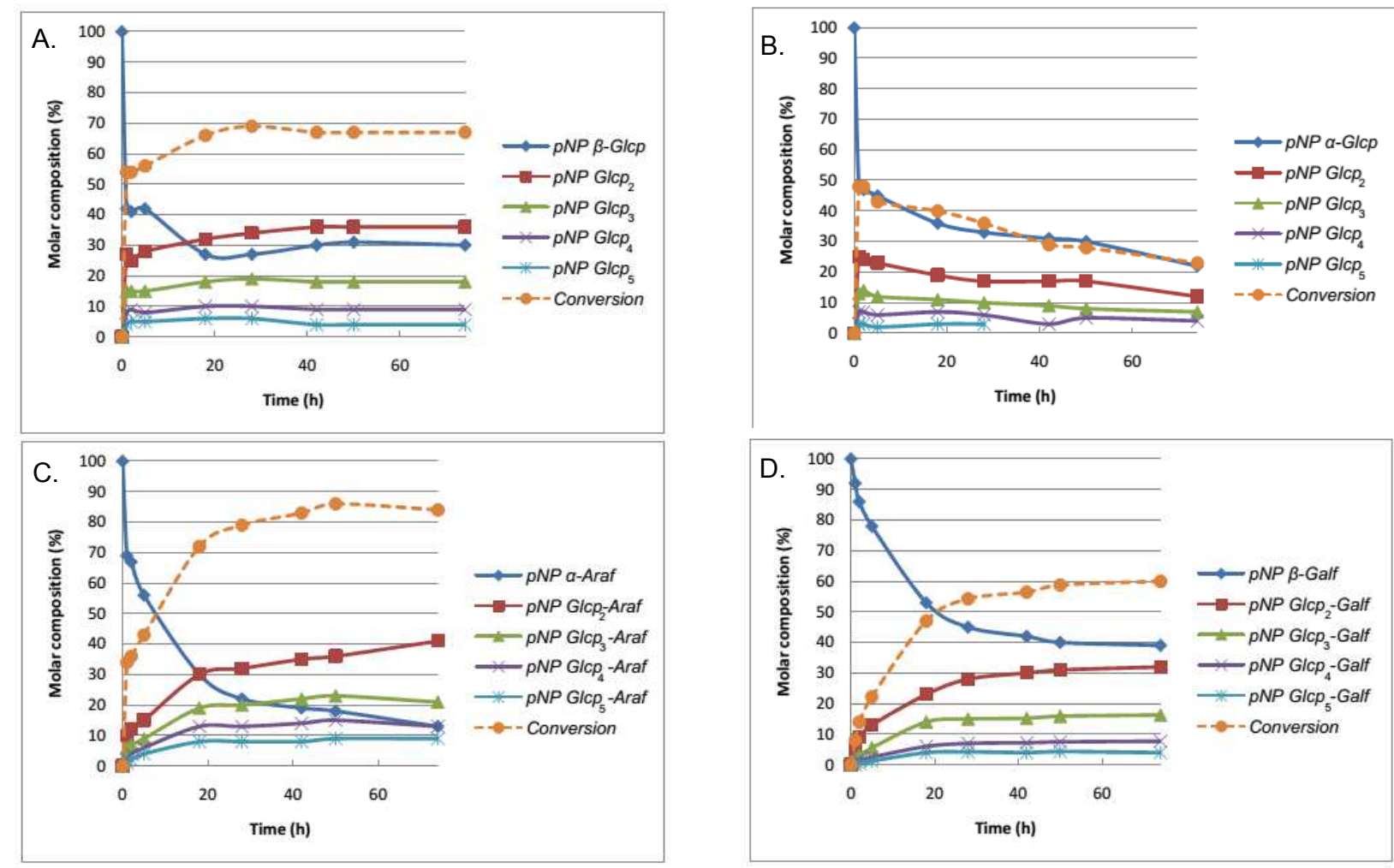

Fig. 3 Kinetic profile of the reaction catalyzed by CGTase between cyclodextrın and 1 (A.), 2 (B.) 3 (C.) and 4 (U.)

The main products of all reactions were isolated for identification. On the chromatograms of the reaction on $p N P \beta-G I c p 2$, it was pointed out the presence of a minor peak at 7.43 minutes next to the major peak at 6.64 minutes. Both peaks had a mass of 463 corresponding to a disaccharide ( $\left.p N P \beta-G \mid c p_{2}\right)$. After isolation and NMR analysis, it was established that the peak at 6.64 min coincided with the pNP $\beta$-maltoside 12 (anomeric proton at 5.21 and 5.09 ppm and anomeric carbons at 102.9 and $102.7 \mathrm{ppm}$ on the ${ }^{1} \mathrm{H}$ and ${ }^{13} \mathrm{C}$ NMR spectra respectively $)^{20,21}$ and the peak at 7.43 minutes resulted from the transglycosylation of a glucose unit in a $\alpha-1,6$-fashion producing the $p N P \beta$-isomaltoside 13 (Fig. 4) as confirmed by the peaks at 5.05 and 4.80 ppm, and at 101.7 and 100.7 ppm on the ${ }^{1} \mathrm{H}$ and ${ }^{13} \mathrm{C}$ NMR spectra, respectively. ${ }^{22}$ The formation of the isomaltoside was also noticeable on the HPLC chromatogram of the reaction on $p N P \alpha-G l c p 1$ but in a lesser extent. As for $p N P$ arabinoside acceptor 3, fractions containing $p N P$ Glcp-Araf and $p N P$ Glcp $p_{2}$-Araf were isolated after reaction on a preparative scale. While the chromatogram also 
showed an additional peak at the base of the major one, both isolated fractions contained only one regioisomer. The isolated disaccharide presented an anomeric proton at $5.71 \mathrm{ppm}$ associated with a carbon at $107.7 \mathrm{ppm}$. Coupling constant $J_{\mathrm{H} 1, \mathrm{H} 2}$ reaches $1.2 \mathrm{~Hz}$, a typical value for an anomeric proton of a furanoside in 1,2-trans configuration. The second anomeric position showed a proton at $4.96 \mathrm{ppm}$ and a carbon at $101.8 \mathrm{ppm}$ representative of a pyranosidic anomeric position with $J_{\mathrm{H} 1-\mathrm{H} 2}$ of $4 \mathrm{~Hz}$ characteristic of a glycopyranosidic bond in 1,2-cis configuration. 2D- ${ }^{1} \mathrm{H}$ NMR $\mathrm{HMBC}$ experiments exhibited also a long range correlation between $\mathrm{H}_{\mathrm{p}}-1$ and $\mathrm{C}_{\mathrm{f}}-3$ indicating a $(1,3)$-glycosidic bond (See ESI). This data pointed unambiguously towards pNP $\alpha$-D-Glcp-(1,3)- $\alpha$-L-Araf 14 as the sole disaccharide isolated from the action of CGTase on 3. Similarly, characterisation of the fraction corresponding to $p N P$ Glc $p_{2}$-Araf allowed the identification of the trisaccharide $p N P$ a-D-Glcp-(1,4)- $\alpha$-D-Glcp$(1,3)$ - $\alpha-L-A r a f 15$ as the unique constituent of this fraction. Isolated yields reach $17 \%$ for the disaccharide and $10 \%$ for the trisaccharide. Those values were slightly higher than the ones obtained after the action of the CGTase on 2. Similarly, pNP $\alpha-D-G l c p-(1,3)-\beta-D-G a l f 16$ and $p N P$-D-Glcp-(1,4)- $\alpha$-D-Glcp-(1,3)- $\beta$-D-Galf 17 were identified as the major products of the glucosylation of $p N P$ Galf (Fig. 4). Here the yields were rather low and other regioisomers [pNP $\alpha-D-G l c p-(1,6)-\beta-D-G a l f$ principally] were detected. In conclusion, the CGTase action on furanosides was slower than on pyranosides but the regioselectivity for $\alpha-(1,3)$ ligation was higher in particular with pNP Araf. However, substitution at C-5 of the furanose led to a drop in the transglycosylation yield and the regioselectivity.

Fig.4 Isolated products and subsequent yields

In order to further optimize the action of the CGTase onto the substrates, microwave activation was attempted to i) accelerate the reaction and ii) improve the transglycosylation yields. $^{23}$ Such protocol should not degrade the enzyme as CGTase of Thermoanaerobacterium $s p$. has the highest thermostability within the CGTase family. ${ }^{24,} 25$ The initial investigation of the microwave radiation (MAR) activation was performed on $p N P$ 
$\alpha$-Glcp 1, and later extended to the other glycosides in order to investigate the effect of the anomeric configuration and the ring size (Table 2). Firstly, the microwave assisted reaction, by drastically reducing the hydrolysis of $p N P$-GIcp 1 otherwise observed, increased the transglycosylation yield from $23 \%$ up to $76 \%$ with a reaction time of 10 seconds instead of 48 hours (Entries 1 and 2). Secondly, the amount of products resulting from the transfer of 1 , 2 or 3 glucosyl residues to 1 was almost tripled (29, 24 and 15\% compared to 10, 7 and $6 \%$, respectively). Furthermore, disproportionation reaction was also affected as the ratio disaccharide / tri- and tetrasaccharides decreased under MAR condition. In addition, by increasing the MAR power from $500 \mathrm{~W}$ (Entry 2) to $1575 \mathrm{~W}$ (Entry 4), no notable variation in the transglycosylation yield was detected. The CGTase of Thermoanaerobacterium $s p$. was denatured above $1575 \mathrm{~W}$ microwave power as only starting materials were detected. Finally, by raising the reaction time from 10 seconds to 30 seconds, the transglycosylation yields dropped from $74 \%$ to $52 \%$ (Entry 3 ). The same conditions were applied with the other $p N P$ glycosides. With the $\beta$-anomer 2 , the transglycosylation yield was slightly improved and again the tri- and tetrasaccharide amounts were higher (Entries 5 to 7 ). Surprisingly no by-products resulting from the transglycosylation of a glucosyl unit in a $\alpha-1,6$-fashion was observed. As for the pNP furanosides $\mathbf{3}$ and $\mathbf{4}$, no improvement in term of conversion and selectivity was observed. Those findings established that microwave-assisted enzymatic reaction did not modify the selectivity and the substrate specificity of the CGTase Therm. It enabled the successful synthesis of both targets pNP glucosides in shorter time and higher yields and thus would provide a practical synthetic method for the glucosylation of specific maltoside derivatives. It also demonstrated the interest of microwave activation in reducing the presence of 1,6-linked byproducts. In addition, this process due to the sole use of aqueous solvents and no hazardous substances can be considered environmentally friendly.

Table 2 Microwave-power effect on the transglycosylation yields of $p$ NP glycosides with the CGTase, over a 10 s period.

\begin{tabular}{|c|c|c|c|c|c|c|c|c|}
\hline \multirow{2}{*}{ Entry } & \multirow{2}{*}{ Acceptor } & \multirow{2}{*}{ Microwave Power (W) } & \multirow{2}{*}{$\begin{array}{c}\text { Trans } \\
\text { glycosylation } \\
(\%)\end{array}$} & \multirow{2}{*}{ Hydrolysis (\%) } & \multicolumn{4}{|c|}{ Conversion $(\%)$} \\
\hline & & & & & $p \mathrm{NP}$ Glc $p_{2}$ & $p$ NP Glc $p_{3}$ & $p$ NP Glc $p_{4}$ & $p \mathrm{NP}$ Glc $p_{5}$ \\
\hline 1 & \multirow{4}{*}{$p$ NP $\alpha-G l c p 1$} & - & 23 & 55 & 10 & 7 & 6 & trace \\
\hline 2 & & 500 & 74 & 0 & 29 & 24 & 15 & 6 \\
\hline 3 & & $500^{\mathrm{a}}$ & 52 & 0 & $\mathrm{nd}^{\mathrm{b}}$ & $\mathrm{nd}^{\mathrm{b}}$ & $\mathrm{nd}^{\mathrm{b}}$ & $\mathrm{nd}^{\mathrm{b}}$ \\
\hline 4 & & 1575 & 78 & 0 & 28 & 25 & 17 & 8 \\
\hline 5 & \multirow{3}{*}{$p$ NP $\beta$-Glc $p 2$} & - & 67 & 0 & 36 & 18 & 9 & 4 \\
\hline 6 & & 500 & 80 & 0 & 30 & 24 & 17 & 9 \\
\hline 7 & & 1575 & 78 & 0 & 28 & 24 & 17 & 9 \\
\hline
\end{tabular}

Finally, the replacement of anomeric nitrophenoxy by an alkoxy chain on Araf and Galf could allow the biocatalyzed synthesis of relevant alkyl oligosaccharides with both pyranose and furanose rings. It would provide an attractive alternative to the chemical synthesis of $\alpha-D-$ Glcp-(1,3)-furanoside bond often tricky to obtain selectively. ${ }^{26}$ Alkyl arabino- and 
galactofuranosides, having a chain length varying from methyl to hexyl for the arabinofuranoside and octyl for the galactofuranoside were thus considered as acceptors (Table 3). They were readily obtained following known procedure by glycosylation of arabinan in presence of an arabinofuranosidase and a proper alcohol. ${ }^{7}$ Alkyl furanosides and cyclodextrin were incubated in presence of Toruzyme ${ }^{\circledR} 3.0 \mathrm{~L}$ for 72 hours according to the protocol previously established. The resulting crude mixture was analyzed by UPLC-MS spectrometry. $[\mathrm{M}-\mathrm{H}]^{-}$Masses corresponding to the different products of transglycosylation were deduced from the mass spectrum allowing the neat visualization of glycoconjugates with up to 4 residues of glucose on the alkyl furanoside (See ESI). However, a certain amount of starting material remained but no hydrolysis could be observed. So the tested alkyl furanosides were confirmed as acceptors of the CGTase even if they did not bear an aromatic ring at the anomeric position.

Preparative scale-up was implemented in order to isolate and identify the different glucosylation products (Table 3). Only the di- and trisaccharides were characterized thanks to NMR experiments. With alkyl arabinofuranosides 11-16, similar isolated yields than with $p N P$ substrates were obtained. The di- and tri-saccharides represented an average of $30 \%$ of the oligosaccharides and were thus the major products of the reaction. The nature of the glycosidic bond was elucidated thanks to HMBC experiments. As previously stated, $\alpha-(1,3)$ bond between the first glucosyl unit and the furanosyl residue was favoured. In contrast, the reaction with octyl Galf 17 as acceptor yielded to a lower amount of di- and trisaccharides confirming the lower affinity of the galactofuranoside for the enzyme. Anyway, in both cases, in only two steps and without protecting groups manipulation, oligosaccharides incorporating a $\alpha$-D-Glcp-(1,3)-furanoside link could be obtained. Such pattern could be found for example as part of exopolysaccharide expressed by some strains of streptococcus pneumonia. ${ }^{27}$ or associated with triterpenoidal saponin extracted from Meryta denhamii seem. ${ }^{28}$ This last compound showed some antihyperglycemic effect and hence demonstrated the therapeutic potential of those scaffolds.

\section{Conclusions}

In conclusion, this paper reported the extensive study of the versatility of CGTase Therm. against acceptors having either a pyranosyl or a furanosyl conformation. Our methodology enabled the enzymatic transglycosylation reaction of a glucosyl unit onto a range of carbohydrate acceptors using readily available donor and biocatalyst, in water and under microwave ${ }^{\circledR}$ irradiation, following an environmentally benign procedure. It demonstrated that the enzyme conserved its catalytic activity independently of the substrate form. Additionally, the application of microwave irradiation proved a positive effect on yields, reaction time and byproduct formation without denaturing the enzyme when pNP pyranoside was used as 
substrate. Interestingly our methodology enabled the enzymatic transglycosylation reaction of a glucosyl unit onto a range of alkyl furanoside acceptors to selectively obtained alkyl $\alpha$ Glcp-(1,3)-Araf or Galf. Such scaffolds need yet to be evaluated for potential surfactant properties or as bacteriostatics.

Table 3 Extension of the glucosylation catalyzed by CGTase to alkyl furanosides

\begin{tabular}{|c|c|c|c|c|c|c|c|}
\hline \multirow{2}{*}{ Entry } & \multirow{2}{*}{ Serie } & \multirow{2}{*}{$\begin{array}{c}\text { Alkyl } \\
\text { furanoside }\end{array}$} & \multirow{2}{*}{$\mathrm{R}^{1}$} & \multirow{2}{*}{$\mathrm{R}^{2}$} & \multirow{2}{*}{$\begin{array}{c}\text { Conversion } \\
(\%)\end{array}$} & \multicolumn{2}{|c|}{$\begin{array}{c}\text { Products (Yield, } \\
\%)\end{array}$} \\
\hline & & & & & & $\mathrm{n}=0$ & $\mathrm{n}=1$ \\
\hline 1 & \multirow{6}{*}{$\alpha$-L-Araf } & 5 & $\mathrm{H}$ & $\mathrm{CH}_{3}$ & 68 & 18 (14) & $25(11)$ \\
\hline 2 & & 6 & $\mathrm{H}$ & $\mathrm{CH}_{3} \mathrm{CH}_{2}$ & 62 & $19(25)$ & $26(14)$ \\
\hline 3 & & 7 & $\mathrm{H}$ & $\mathrm{CH}_{3}\left(\mathrm{CH}_{2}\right)_{2}$ & 73 & $20(21)$ & 27 (13) \\
\hline 4 & & 8 & $\mathrm{H}$ & $\mathrm{CH}_{3}\left(\mathrm{CH}_{2}\right)_{3}$ & 82 & 21 (19) & 28 (12) \\
\hline 5 & & 9 & $\mathrm{H}$ & $\mathrm{CH}_{3}\left(\mathrm{CH}_{2}\right)_{4}$ & 88 & 22 (19) & $29(11)$ \\
\hline 6 & & 10 & $\mathrm{H}$ & $\mathrm{CH}_{3}\left(\mathrm{CH}_{2}\right)_{5}$ & 58 & $23(25)$ & $30(10)$ \\
\hline 7 & $\beta$-D-Galf & 11 & $\overline{\mathrm{CH}_{2} \mathrm{O}}$ & $\overline{\mathrm{ICH}_{3}\left(\mathrm{CH}_{2}\right)_{7}}$ & 16 & $24(5)$ & $31(3)$ \\
\hline
\end{tabular}

\section{Acknowledgement}

We are grateful to Novozymes A/S (Bagvaerd, Denmark) for the gift or Toruzyme ${ }^{\circledR} 3.0 \mathrm{~L}$, to Rennes Metropole for a mobility fellowship to A. P. and to "Région Bretagne" and CNRS for financial supports.

\section{Experimental section}

\section{Materials}

All reagents were purchased from commercial sources and were used without further purification unless noted. Thermonanerobacter sp. CGTase (Toruzyme ${ }^{\circledR} 3.0 \mathrm{~L}$ ) was a gift of Novozymes A/S (Bagvaerd, Denmark).

\section{Kinetics of the enzymatic reaction with pNP glycosides}

The synthesis ability of the CGTases from Thermoanaerobacter $s p$. was previously investigated and the reaction with the enzyme was optimized to efficiently produce the primary coupling product. Typically, CGTase $(10 \mu \mathrm{L}, 2.34 \mathrm{mg} / \mathrm{mL})$ was added to $1.5 \mathrm{~mL}$ microtubes containing $\square$-cyclodextrin (100 mg, $0.1 \mathrm{mM})$ and various carbohydrates $(0.2 \mathrm{mM})$ in of $50 \mathrm{mM}$ phosphate buffer, $\mathrm{pH} 6.0(1 \mathrm{~mL})$ at $50^{\circ} \mathrm{C}$. The reaction mixtures were incubated in a thermomixer (Eppendorf) during 72 h. $50 \mu \mathrm{L}$ samples were withdrawn at different intervals and diluted with $950 \mu \mathrm{L}$ of acetonitrile/water (50:50) followed by a filtration before chromatography analysis.

\section{HPLC analysis}


Chromatographic analysis were carried out on an Agilent 1200 HPLC system (Agilent Technologies, Mexico), equipped with a ChemStation software, a micro-vacuum degasser G1322A, a quartenary pump G1311A, an autosampler G1329A, a thermostatic column compartment G1316A, and a diode array detector G1315B. An analytical Altech Prevail $^{\mathrm{TM}}$ carbohydrate ES column (Analytical, 4.6x250 mm, $5 \mu \mathrm{m}$, Grace) was used for chromatographic separation at $35{ }^{\circ} \mathrm{C}$. Using acetonitrile (mobile phase A) and purified and distilled water (mobile phase $B$ ) at a flow rate of $1 \mathrm{~mL} / \mathrm{min}$, HPLC analysis started with $20 \% \mathrm{~B}$ followed by gradient to $50 \%$ B over $40 \mathrm{~min}$, then by a gradient step for 1 min back to $20 \% \mathrm{~B}$, before isocratic elution with starting conditions within $30 \mathrm{~min}$. The injection volume of each sample was $10 \mu \mathrm{L}$. Simultaneous monitoring was performed at 300,368 and $400 \mathrm{~nm}$.

\section{Transglycosylation reactions with glycosidic acceptor in a preparative scale}

Reaction conditions were implemented as previously described in a $1 \mathrm{~mL}$ final volume using a molar ratio glycoside/ $\beta$-cyclodextrin $3 / 1$ and CGTase $(10 \mu \mathrm{L}, 2.34 \mathrm{mg} / \mathrm{mL})$. The resulting mixture was incubated at $50{ }^{\circ} \mathrm{C}$ during $72 \mathrm{~h}$. Reaction mixture was lyophilized and the residue was purified by silica gel flash chromatrography using a eluant gradient AcOEt$\left(\mathrm{AcOH} / \mathrm{H}_{2} \mathrm{O}, 1: 1\right)$ from $90: 5$ to $60: 40$. Elution of the products was monitored by UV detection and by TLC, Fractions corresponding to individual products were collected, evaporated and lyophilized.

\section{References}

1. A. Ranoux, L. Lemiegre, M. Benoit, J.-P. Guegan and T. Benvegnu, Eur. J. Org. Chem., 2010, 1314-1323.

2. I. Chlubnova, D. Filipp, V. Spiwok, H. Dvorakova, R. Daniellou, C. Nugier-Chauvin, B. Kralova and V. Ferrieres, Org. Biomol. Chem., 2010, 8, 2092-2102.

3. L. Legentil, J.-L. Audic, R. Daniellou, C. Nugier-Chauvin and V. Ferrières, Carbohydr. Res., 2011, 346, 1541-1545.

4. B. K. Singh, A. K. Yadav, B. Kumar, A. Gaikwad, S. K. Sinha, V. Chaturvedi and R. P. Tripathi, Carbohydr. Res., 2008, 343, 1153-1162.

5. B. L. Wilkinson, H. Long, E. Sim and A. J. Fairbanks, Bioorg. Med. Chem. Lett., 2008, 18, 6265-6267.

6. M. Suleman, J.-P. Gangneux, L. Legentil, S. Belaz, Y. Cabezas, C. Manuel, R. Dureau, O. Sergent, A. Burel, F. Daligault, V. Ferrières and F. Robert-Gangneux, Antimicrob. Agents Chemother., 2014, 58, 2156-2166.

7. R. Daniellou, C. Nugier-Chauvin, V. Ferrieres, A. Pennec and I. Chlubnova, PCT Int. Appl Pat., WO2013160205A1, 2013.

8. T. Lipiński, C. Jones, X. Lemercinier, A. Korzeniowska-Kowal, M. Strus, J. Rybka, A. Gamian and P. B. Heczko, Carbohydr. Res., 2003, 338, 605-609. 
9. V. M. Marshall, H. Dunn, M. Elvin, N. McLay, Y. Gu and A. P. Laws, Carbohydr. Res., 2001, 331, 413-422.

10. M. Olszewska and M. Wolbis, Pol. J. Chem., 2002, 76, 967-974.

11. B. Henrissat and G. Davies, Curr. Opin. Struct. Biol., 1997, 7, 637-644.

12. Q. Qi and W. Zimmermann, Appl. Microbiol. Biotechnol., 2005, 66, 475-485.

13. S. Kitahata, in Enzyme chemistry and molecular biology of amylases and related enzymes, The Amylase Res. Soc., Japan, 1995, pp. 6 - 17.

14. W. Wongsangwattana, J. Kaulpiboon, K. Ito and P. Pongsawasdi, Process Biochem. (Amsterdam, Neth.), 2010, 45, 947-953.

15. A. Nakamura, K. Haga and K. Yamane, FEBS Lett., 1994, 337, 66-70.

16. D. Svensson, S. Ulvenlund and P. Adlercreutz, Green Chem., 2009, 11, 1222-1226.

17. S.-H. Yoon and J. F. Robyt, Carbohydr. Res., 2006, 341, 210-217.

18. W.-b. Zhou, B. Feng, H.-z. Huang, Y.-j. Qin, Y.-z. Wang, L.-p. Kang, Y. Zhao, X.-n. Wang, Y. Cai, D.-w. Tan and B.-p. Ma, Carbohydr. Res., 2010, 345, 1752-1759.

19. J. C. M. Uitdehaag, K. H. Kalk, B. A. van der Veen, L. Dijkhuizen and B. W. Dijkstra, J. Biol. Chem., 1999, 274, 34868-34876.

20. W. Hakamata, T. Nishio, R. Sato, T. Mochizuki, K. Tsuchiya, M. Yasuda and T. Oku, J. Carbohydr. Chem., 2000, 19, 359-377.

21. S. J. Gebbie, I. Gosney, P. R. Harrison, I. M. F. Lacan, W. R. Sanderson and J. P. Sankey, Carbohydr. Res., 1998, 308, 345-348.

22. A. Tramice, G. Andreotti and A. Trincone, Mar. Biotechnol., 2011, 13, 773-781.

23. D. D. Young, J. Nichols, R. M. Kelly and A. Deiters, J. Am. Chem. Soc., 2008, 130, 10048-10049.

24. R. Ong, K. Goh, N. Mahadi, O. Hassan, R. Rahman and R. Illias, J. Ind. Microbiol. Biotechnol., 2008, 35, 1705-1714.

25. B. Rejasse, S. Lamare, M.-D. Legoy and T. Besson, J. Enzyme Inhib. Med. Chem., 2007, 22, 519-527.

26. L. Gandolfi-Donadio, C. Gallo-Rodriguez and R. M. de Lederkremer, J. Org. Chem., 2002, 67, 4430-4435.

27. C.-H. Lee and C. E. Frasch, Anal. Biochem., 2001, 296, 73-82.

28. E. H. Abdel Rahman, A. R. Abdel Monem and A. A. Sleem, Pharmacogn. J., 2012, 4, 56-59. 